\title{
Efficacy of low-protein diet for diabetic nephropathy: a systematic review of randomized controlled trials
}

Huan-gao Zhu' ${ }^{1 \dagger}$, Zhao-shun Jiang ${ }^{3 \dagger}$, Pi-yun Gong ${ }^{1}$, Dong-mei Zhang ${ }^{2}$, Zhi-wei Zou', Qian-Zhang ${ }^{1}$, Hui-mei Ma', Zhen-gang Guo ${ }^{5}$, Jun-yu Zhao ${ }^{4}$, Jian-jun Dong ${ }^{*^{*}}$ and Lin-Liao ${ }^{4^{*}}$

\begin{abstract}
Background: A low-protein diet (LPD) is believed to be beneficial in slowing the progression of kidney disease. It is reported that low protein diet can improve protein, sugar and lipid metabolism, and reduce the symptoms and complications of renal insufficiency. However, there has been controversial regarding the effects of protein restriction on diabetic nephropathy (DN).
\end{abstract}

Objective: To investigate the efficacy of LPD on renal function in patients with type 1 or 2 DN by meta-analysis of randomized controlled trials (RCTs).

Design: PubMed, MEDLINE, EMBASE and China National Knowledge Infrastructure databases were searched. Eleven randomized controlled trials met the inclusion criteria, of which 10 were English and 1 was Chinese. The primary outcome was a change in glomerular filtration rate (GFR). The secondary outcome was a change in proteinuria. Random-effects models were used to calculate the standardized mean difference (SMD) and the corresponding 95\% confidence intervals (CI). Subgroup analyses were also performed.

Results: Our research indicated that LPD was not associated with a significant improvement in GFR $\left(1.59 \mathrm{ml} \cdot \mathrm{min}^{-1} \cdot 1.73 \mathrm{~m}^{-2}, 95 \% \mathrm{Cl}-0.57,3.75, \mathrm{I}^{2}=76 \% ; p=0.15\right)$. This effect was consistent across the subgroups regardless of type of diabetes, course of diabetes and intervention period. Our results also showed that there was no significant difference on improvement of proteinuria in patients of LPD and those in normal-protein diet groups $\left(-0.48,95 \% \mathrm{Cl}-1.70,0.74, \mathrm{I}^{2}=94 \%, p=0.44\right)$. Subgroup analysis revealed that LPD resulted in increased excretion of proteinuria in patients with type 2 diabetes $\left(1.32,95 \% \mathrm{Cl} 0.17,2.47, \mathrm{I}^{2}=86 \%, p=0.02\right)$.

Conclusion: The present research showed that LPD was not significantly associated with improvement of renal function in patients with either type 1 or 2 diabetic nephropathy. Although these results do not completely eliminate the possibility that LPD is beneficial for patients with diabetic nephropathy, it does not seem to be significant benefit to renal function.

Keywords: Diabetic nephropathy, Protein restriction, Low-protein diet

\footnotetext{
* Correspondence: Dongjianjun@sdu.edu.cn; cwc_II@sdu.edu.cn

${ }^{\dagger}$ Huan-gao Zhu and Zhao-shun Jiang contributed equally to this work.

'Division of Endocrinology, Qilu Hospital of Shandong University, Jinan,

Shandong, China

${ }^{4}$ Division of Endocrinology, Shandong Provincial Qianfoshan Hospital, Jinan,

Shandong, China

Full list of author information is available at the end of the article
}

(c) The Author(s). 2018 Open Access This article is distributed under the terms of the Creative Commons Attribution 4.0 International License (http://creativecommons.org/licenses/by/4.0/), which permits unrestricted use, distribution, and reproduction in any medium, provided you give appropriate credit to the original author(s) and the source, provide a link to the Creative Commons license, and indicate if changes were made. The Creative Commons Public Domain Dedication waiver (http://creativecommons.org/publicdomain/zero/1.0/) applies to the data made available in this article, unless otherwise stated. 


\section{Background}

Diabetic nephropathy, develops in nearly half of patients with diabetes, is the leading cause of end-stage kidney disease (ESRD) worldwide, and is also substantially associated with increased risk of cardiovascular mortality [1, 2]. Multifactorial management have been proposed for diabetic nephropathy, such as diet therapy and well control of blood glucose, blood pressure and dyslipidemia. Among these, diet therapy has been suggested as the mainstay in the treatment of diabetic nephropathy. To delay the progression of ESRD in patients with diabetes, low-protein diet (LPD) is recommended by the American Diabetes Association guidelines to delay the progression of ESRD in patients with diabetes in 2008 [3-5].Since then, numerous studies focusing on the the efficacy of LPD for diabetic nephropathy have been performed. However, the results remains controversial [6-12]. Some studies reported the beneficial effects of LPD, which significantly slowed the increase in urinary albumin concentration or declined the glomerular filtration rate (GFR) or creatinine filtration rate (CCR) [13, 14]. While several researches revealed the opposite $[15,16]$. Therefore, we conducted a systematic review and meta-analysis of randomized controlled trials (RCTs) to explore the effect of LPD on the progression of renal dysfunction and albuminuria in type 1 or type 2 diabetic patients with overt nephropathy.

\section{Methods}

\section{Search strategy and inclusion criteria}

We searched RCTs via PubMed, Medline, Embase and China National Knowledge Infrastructure databases, ClinicalTrials.gov from inception to December 2016 to identify relevant citations. The key words of the first step were "protein-restricted, diet" OR "diet, protein-restricted" OR "low protein diet" AND "diabetic nephropathies". From these searches, studies evaluating the effects of LPD compared with control diet among diabetic patients were identified. Eleven studies met the inclusion criteria for our systematic review: 1.published in full text 2.use of a randomized control group 3.availability of outcome data for changes in GFR or CCR, and albuminuria or proteinuria in patients with type 1 or 2 diabetic nephropathy 4.RCTs of crossover design were excluded. Of the 11 studies, 10 included trials were published in English-language medical journals.

\section{Data extraction}

We extracted data related to the year of publication, patients and participants' characteristics (age, sex, type and duration of diabetes or diabetic nephropathy), and outcomes (GFR, CCR or evaluated GFR, proteinuria or similar index, and serum albumin concentration). Also, we extracted data for patients' compliance by integrating the data on actual protein intake evaluated for each study. We utilized these results to appraise the study quality and subsequent subgroup analyses were performed. The primary outcome was a change in GFR or $\mathrm{CCr}$ from baseline till the end of the diet intervention. The secondary outcome was the extraction of change in proteinuria.

\section{Statistical analysis}

Data were combined by means of a random-effects model. The SD (standard deviation) were imputed by using interquartile ranges and full ranges. The methods of calculating the change-from-baseline SD are referenced in the Cochrane Handbook [17]. The standardized mean difference (SMD), which is calculated by dividing the mean values by the SD and which can be used to compare studies that report continuous outcomes by using different scales, was used to pool results from all studies that reported untransformed changes in urinary protein excretion.

\section{Risk of bias assessment}

Risk of bias of included studies was estimated using the Cochrane Collaboration's "risk of bias" assessment tool [18]. We assessed seven aspects: (1) blinding of participants, (2) allocation concealment, (3) sequence generation, (4) blinding of outcome assessment, (5) selective outcome reporting, (6) incomplete outcome data, (7) other bias by patients' diet compliance. Since this study aimed to investigate the clinical effect of dietary intervention which encourages patients' lifestyle modification, we considered that patients' diet compliance was the most critical factor to generate risk of bias.

\section{Results \\ Search results}

As shown in Fig. 1, we initially acquired 324 records through electrical database search. Of these, two hundred and twenty-six studies were excluded after evaluation of abstracts. Fifty-six non-random studies were excluded; and we selected 42 full text articles for detailed assessment for eligibility. Among these, we excluded thirty-one studies: twelve studies owing to lack of comparison, nine studies due to crossover design, ten studies were mutilple reports. Finally, we included $11 \mathrm{RC}$ Ts reporting the effects of LPD in diabetic patients.

\section{Characteristics of included studies}

The included studies evaluated the effects of LPD in 687 diabetic patients. Study patients were middle-aged men and women, mostly obese or 


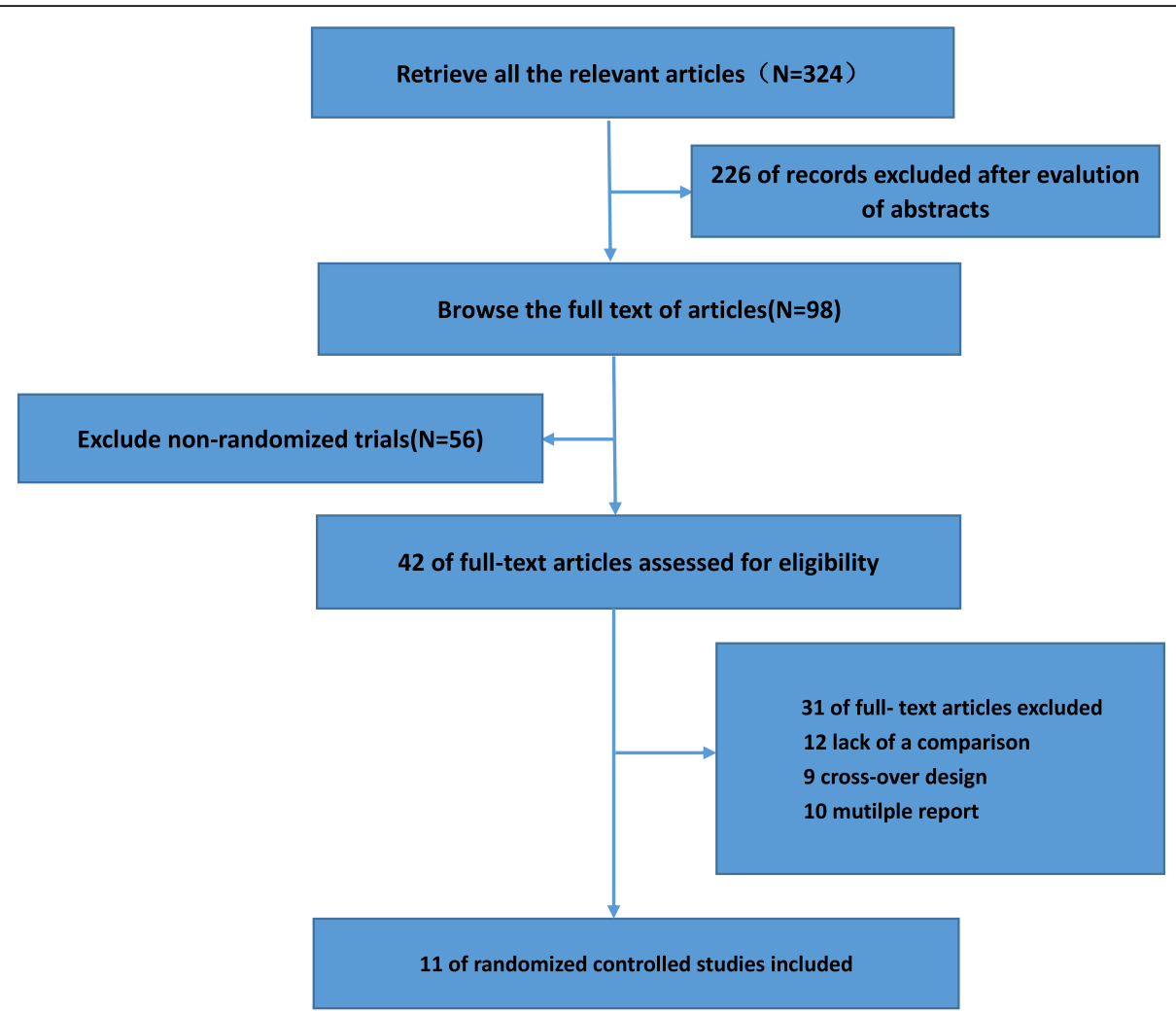

Fig. 1 Flow diagram of the process for study selection

overweight (Tables 1 and 2). Five studies included patients with Type 1 diabetes, whereas six studies included patients with type 2 diabetes. Two studies included patients with both type 1 and type 2 diabetes patients and provided no separate information. Intervention period ranged from 2 to 60 months. However, allocation concealment was unclear in about half of the studies (Table 3). Although the outcome assessment was not blinded to the assessors in any of the studies, the risk of bias is considered to be small since the outcome is objective.

\section{Effects of low-protein diet on kidney function}

There were no significant changes observed in GFR with the effects of LPD (95\% CI-0.57, 3.75; $P=0.15$, Fig. 2). We found significantly evident heterogeneity across the studies $\left(\mathrm{I}^{2}=76 \%, p<0.00001\right)$. However, the funnel plot showed no major asymmetricity (Fig. 3.)

\section{Effects of LPD on proteinuria or albuminuria}

Five different measurements of protein excretion were described in the trials: albumin excretion rate $(\mathrm{mg} / 24 \mathrm{~h})$, microalbuminuria $(\mathrm{g} / \mathrm{d})$, urine albumin excretion (UAE) $(\mathrm{mg} / 24 \mathrm{~h}), 24 \mathrm{~h}$ proteinuria $(\mathrm{g} / 24 \mathrm{~h})$, and albuminuria $(\mathrm{mg} / 24 \mathrm{~h})$. Therefore, the SMD was used to compare these diverse measures. The standard mean difference showed no significant change in proteinuria after LPD $(-0.48,95 \%$ CI -1.70 to $0.74 ; p=0.44$; Fig. 4$)$.

\section{Subgroup analyses}

Subgroup analysis was performed according to the clinical characteristics and study quality (Table 4). There were no significant differences observed in the changes in GFR between the subgroups based on the course of diabetes (1.76, 95\% CI-0.5, 4.02, $p=0.98$ ), type of diabetes (1.59, 95\% CI-0.57, 3.75, $p=0.15)$, BMI (1.02, 95\% CI-1.23, 3.28, $p=0.37)$ and intervention period $(0.18,95 \%$ CI-1.36, 1.72 , $p=0.82)$. Changes in proteinuria demonstrated significant difference in the subgroups of type 2 diabetes (1.32, 95\% $0.17,2.47, p=0.02$; Fig. 5). There was no significant difference observed between the subgroups of intervention period $(-0.20,95 \%-1.43,1.02, p=0.24)$, course of diabetes $(-0.48,95 \%$ CI-1.70, 0.74, $p=0.05)$ and BMI $(-0.13,95 \%$ CI $1.62,1.35, p=0.66$ ).

\section{Discussion}

In the present research, we included 11 RCTs that investigated the efficacy of LPD intervention in patients with type 1 or 2 diabetic nephropathy. Overall results of this 


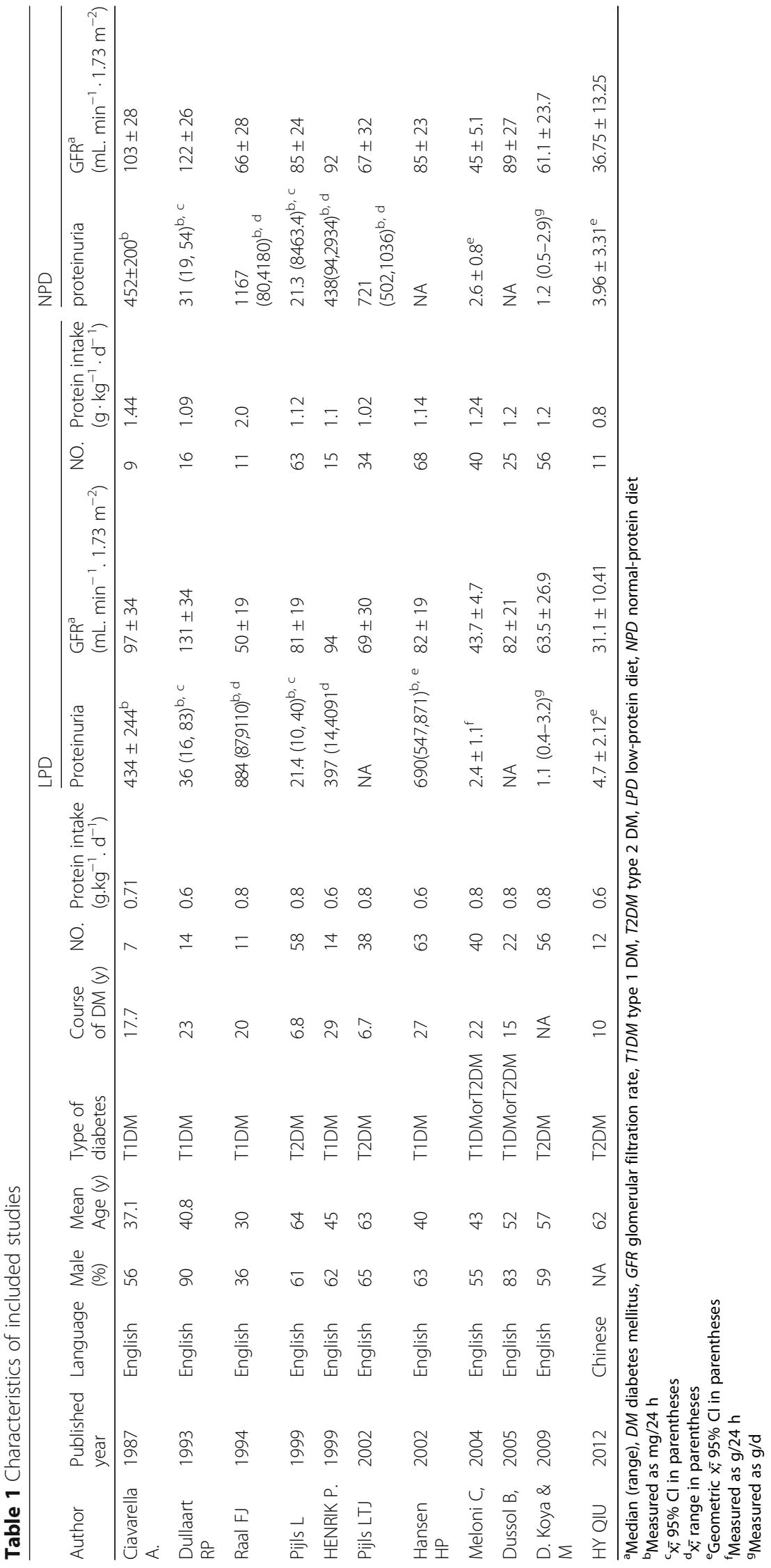


Table 2 Characteristics of included studies

\begin{tabular}{|c|c|c|c|c|}
\hline Author (year) & NO. & $\begin{array}{l}\mathrm{BMl} \\
\left(\mathrm{kg} / \mathrm{m}^{2}\right)\end{array}$ & $\begin{array}{l}\mathrm{HbA} 1 \mathrm{C} \\
(\%)\end{array}$ & $\begin{array}{l}\text { Intervention } \\
\text { period (months) }\end{array}$ \\
\hline Ciavarella A.1987 [35] & 16 & NA & 7.3 & 12 \\
\hline Dullaart RP.1993 [36] & 30 & 24.1 & 7.8 & 24 \\
\hline Raal FJ.1994 [37] & 31 & 24.9 & 13.0 & 6 \\
\hline Pijls L 1999 [38] & 121 & 27.7 & 7.7 & 12 \\
\hline HENRIK P. 1999 [39] & 29 & 25 & 8.5 & 2 \\
\hline Pijls LTJ 2002 [40] & 72 & 27.8 & 7.7 & 28 \\
\hline Hansen HP 2002 [13] & 131 & 25 & 9.8 & 48 \\
\hline Meloni C 2004 [41] & 80 & 33.5 & 7.0 & 3 \\
\hline Dussol B 2005 [42] & 47 & NA & 8.1 & 24 \\
\hline D. Koya \& M 2009 [43] & 112 & 24.6 & 7.6 & 60 \\
\hline Hong yu QIU 2012 [44] & 23 & NA & 6.3 & 12 \\
\hline
\end{tabular}

$B M I$ body mass index, HbA1C haemoglobin A1C

meta-analysis indicated that, when compared with normal-protein diet, intake of LPD demonstrated no protective effect on diabetic nephropathy neither on improving GFR $\left(1.59 \mathrm{ml} \cdot \mathrm{min}^{-1} \cdot 1.73 \mathrm{~m}^{-2}, 95 \%\right.$ CI -0.57 , $\left.3.75, \mathrm{I}^{2}=76 \% ; p=0.15\right)$ nor proteinuria $(-0.48,95 \%$ CI-1.70, 0.74, $\mathrm{I}^{2}=94 \%, p=0.44$ ).

Diabetic nephropathy is the leading cause of progressive kidney disease, as the end stage renal disease consumed huge sum of money every year. Therefore, prevention of diabetic nephropathy is a major public health challenge. LPD is recommended by several guidelines as a basic measure for the treatment of diabetic nephropathy. However, the effect of LPD on diabetic nephropathy still remained controversial, and the results of our present study demonstrated a great meaning.

Previously, a number of studies have explored the role of LPD in patients with diabetic nephropathy.
Several studies $[19,20]$ have evaluated the effects of LPD in animal models and indicated that LPD is renoprotective effects in renal diseases, even in advanced diabetic nephropathy via restoring autophagy through the suppression of the mechanistic target of rapamycin complex 1 (mTORC1) pathway in type 2 diabetes animal model [21]. One possible explanation is related to the amount of protein intake. Protein overload increases the secretion of glucagon from the pancreas, and the glucagon in turn induces direct dilatation of afferent arterioles in the glomeruli and subsequently increases intraglomerular pressure [22]. Protein overload also increases the secretion of insulin-like growth factor-1 (IGF-1) from the liver [23], and IGF-1 acts as a potent vasodilator of the renal vessels [24, 25]. Another possible explanation for the positive effect of LPD in diabetic nephropathy is linked to the renin-angiotensinsystem (RAS). Protein overload activates RAS, whereas LPD inhibits the intrarenal RAS [26-28]. Some studies demonstrated that blockade of RAS with either Angiotensin-Converting Enzyme Inhibitors (ACE-Is) or angiotensin receptor blockers (ARBs) slows down (but does not completely stop) the progression of diabetic nephropathy. The study published in BMJ Open concluded that a LPD was associated with a significant improvement in GFR $(5.82 \mathrm{ml} / \mathrm{min} / 1.73 \mathrm{~m} 2,95 \%$ CI 2.30 to $9.33, \mathrm{I} 2=92 \% ; n=624$ ). While this study indicated that LPD was not associated with a significant improvement in GFR $\left(1.59 \mathrm{ml} \cdot \mathrm{min}^{-1} \cdot 1.73 \mathrm{~m} 2\right.$, $95 \%$ CI $-0.57,3.75, \mathrm{I} 2=76 \% ; p=0.15$ ). In the study we included, there was an article (Chinese article) that did not support the benefits of a low-protein diet, and the study published in BMJ Open did not retrieve this article. When we analyzed all the data included in the study, the weight of the data in this

Table 3 Risk of bias assessment

\begin{tabular}{|c|c|c|c|c|c|c|c|}
\hline Study & $\begin{array}{l}\text { Blinding of } \\
\text { participants }\end{array}$ & $\begin{array}{l}\text { Allocation } \\
\text { concealment }\end{array}$ & $\begin{array}{l}\text { Sequence } \\
\text { generation }\end{array}$ & $\begin{array}{l}\text { Blinding of } \\
\text { outcome } \\
\text { assessment }\end{array}$ & $\begin{array}{l}\text { Selective } \\
\text { outcome } \\
\text { reporting }\end{array}$ & $\begin{array}{l}\text { Incomplete } \\
\text { outcome data }\end{array}$ & $\begin{array}{l}\text { Other bias by } \\
\text { patients' diet } \\
\text { compliance }\end{array}$ \\
\hline Ciavarella A. & Y & Y & Y & Unclear & Unclear & $N$ & N \\
\hline Dullaart RP & Y & Unclear & Y & Unclear & Unclear & N & N \\
\hline Raal FJ & Y & Y & Y & Unclear & Unclear & N & N \\
\hline Pijls L & Y & Unclear & Y & Unclear & Unclear & $\mathrm{N}$ & N \\
\hline HENRIK P. & Y & Y & Y & Unclear & Unclear & $N$ & N \\
\hline Pijls LTJ & Y & Unclear & Y & Unclear & Unclear & Y & N \\
\hline Hansen HP & Y & Y & Y & Unclear & Unclear & N & N \\
\hline Meloni C, & Y & Y & Y & Unclear & Unclear & Y & N \\
\hline Dussol B, & Y & Unclear & Y & Unclear & Unclear & Y & N \\
\hline D. Koya \& M & Y & Y & Y & Unclear & Unclear & Y & N \\
\hline Hong yu QIU & Y & Unclear & Y & Unclear & Unclear & Y & N \\
\hline
\end{tabular}

$Y$ yes, $N$ no 


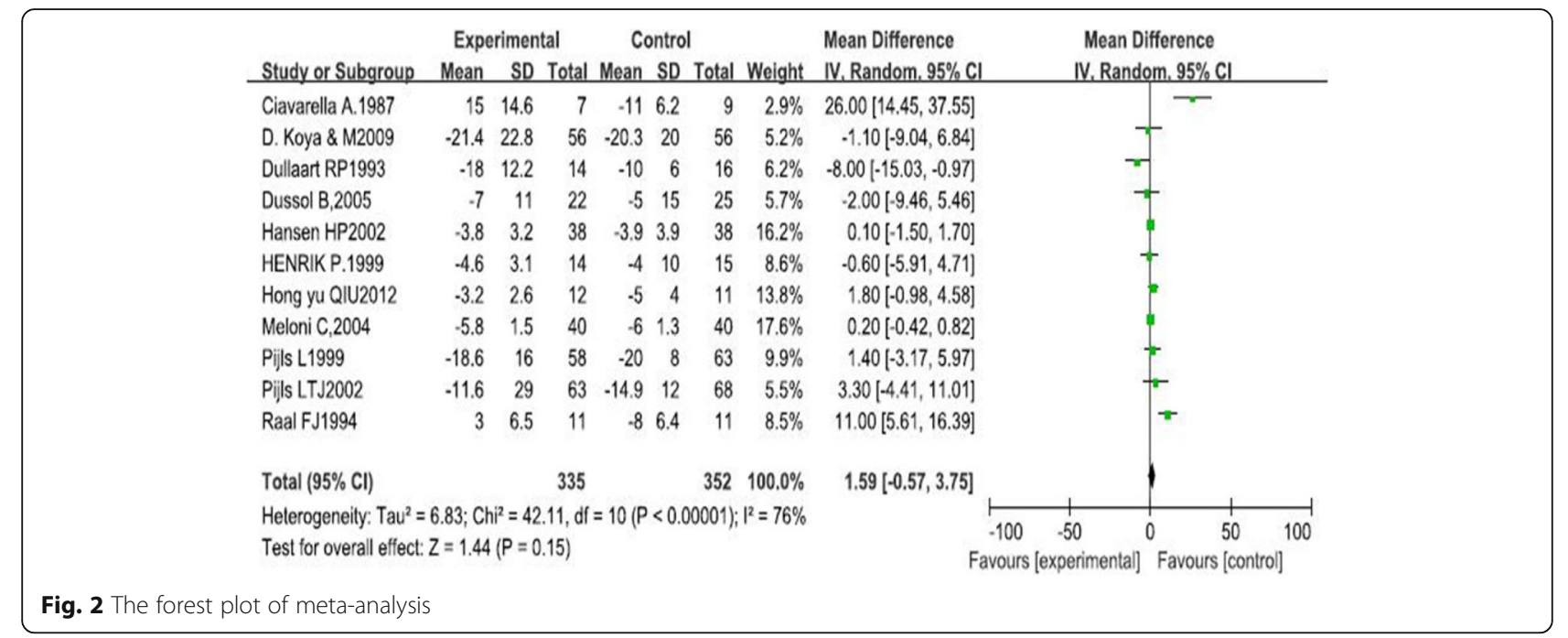

article is $13.8 \%$ (Fig. 1), which is a relatively high proportion. So we thought that the data from this study led to the final synthesis.

Unfortunately, a few clinical trials have reported disappointing results. A large-scale observational study that included 6213 individuals with type 2 diabetes found no clear benefits on renal parameters from LPD [29].The reason for these inconsistencies of the LPD benefits in diabetic nephropathy worth been further explored. As we all know, in clinical practice, the estimated GFR (eGFR) is the common indicator for the assessment of kidney function [30, 31]. But the measurement of creatinine to determine the eGFR has some limitations for the risk prediction, particularly in patients with reduced muscle mass [32]. Therefore, muscle loss can be misrepresented as an improvement in renal function.
Additionally, dietary protein levels influence the blood sugar levels in both human and animal experiments [33]. These are the main confounding factors that affect the consistency in the outcomes of clinical studies.

In our research, crossover trials were excluded. Dr. Freeman pointed out that the crossover strategy is flawed and that it often gave rise to biased conclusions [34]. Given the fact that the crossover design may mask the effects of LPD on renal function, hence we excluded studies with crossover designs from the present study. Besides, the included number of patients was larger.

The significant benefits of LPD on renal diseases in animal and human studies did not impact the renoprotective strategies against diabetic nephropathy. On the basis of the available evidence in the literature and our

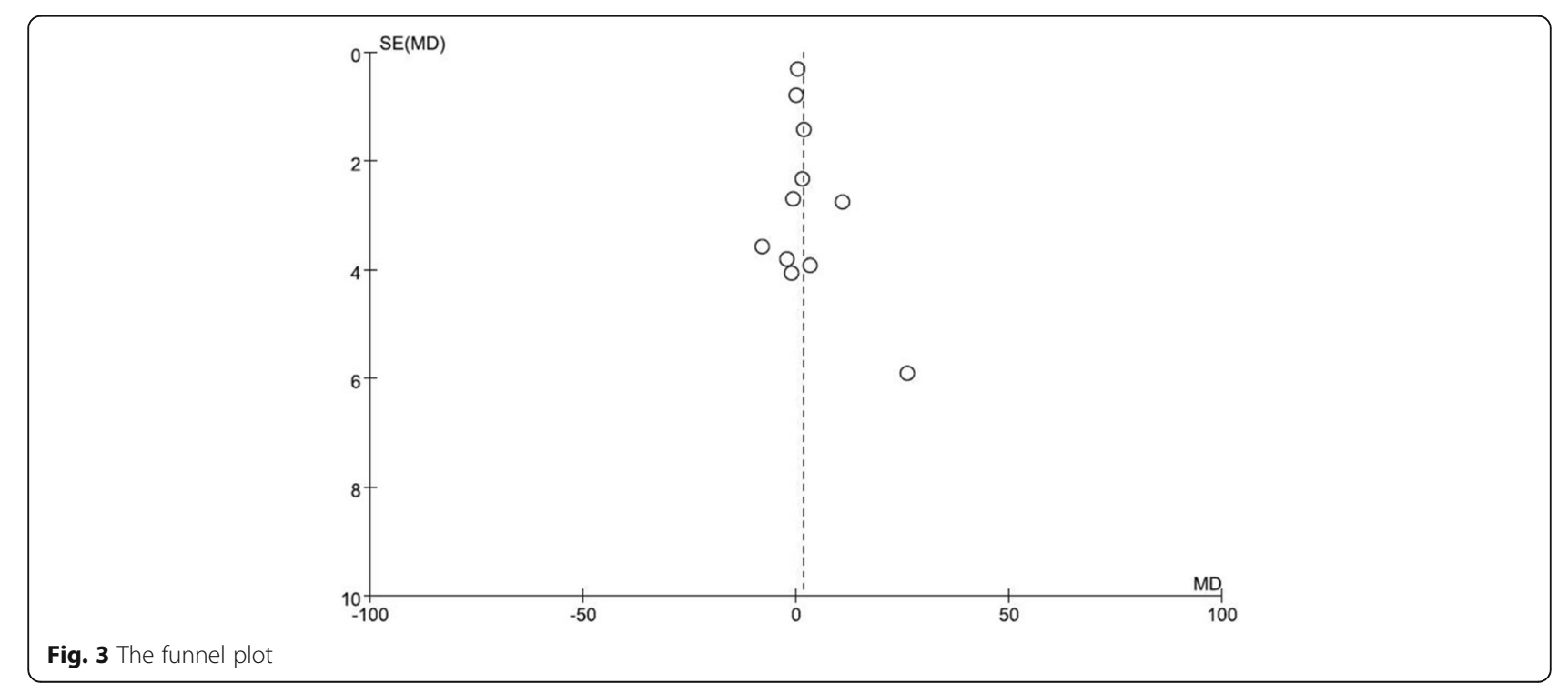




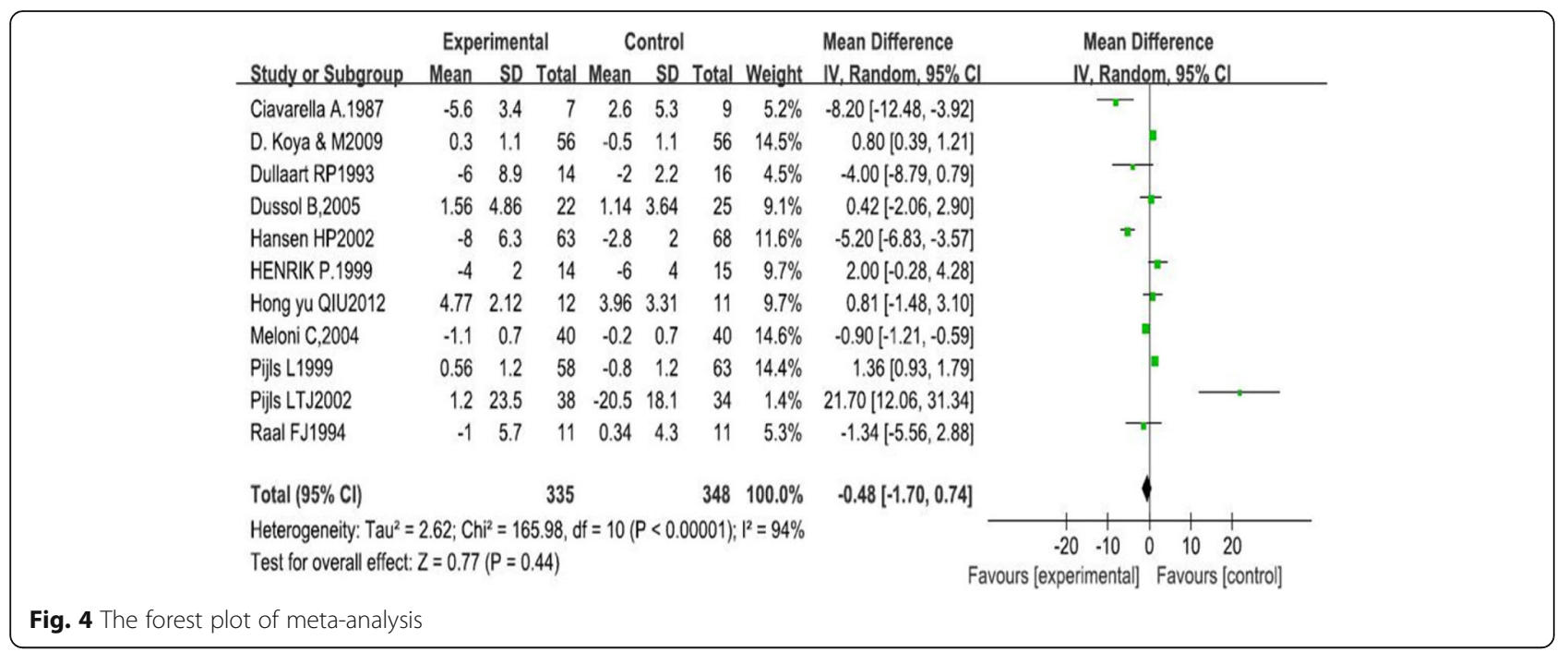

study, there is no strong evidence for introducing a routine LPD as the standard nutritional intervention in diabetic nephropathy.

Our research has several advantages over previous studies. Firstly, our research includes Chinese and English databases, which are not available in the previously published study. Secondly, the most recent study was published 5 years ago. Our study incorporates the latest findings and is now a more comprehensive one. In addition, our study analyzed diabetes patients with different course of disease and different intervention time of low protein diet in detail.
Although the present analysis was based on RCTs, it has some limitations. There was considerable variation in the study subjects (type 1 or type 2 diabetic nephropathy), level of reduction of dietary protein, outcome analysis (GFR and proteinuria), and duration of study. These differences could explain some of the heterogeneity among the trials. Anyway, our research showed that LPD was not associated with a significant improvement of renal function in patients with both type 1 and type 2 diabetic nephropathy. Although these results do not completely eliminate the possibility that LPD is beneficial for patients with diabetic nephropathy, it does not seem to be significant benefit to renal function.

Table 4 Subgroup analyses for clinical characteristics and study quality

\begin{tabular}{|c|c|c|c|c|c|c|}
\hline \multirow[b]{2}{*}{ Subgroups } & \multicolumn{3}{|l|}{ GFR } & \multicolumn{3}{|l|}{ Proteinuria } \\
\hline & Mean difference $(95 \% \mathrm{Cl})$ & $1^{2}(\%)$ & $\overline{p \text { Value }}$ & Mean difference $(95 \% \mathrm{Cl})$ & $\mathrm{I}^{2}(\%)$ & $p$ Value \\
\hline \multicolumn{7}{|l|}{ Type of diabetes } \\
\hline T1DM & $4.46(-2.59,11.51)$ & 90 & 0.21 & $-3.23(-7.03,0.58)$ & 87 & 0.1 \\
\hline T2DM & $1.61(-0.57,3.79)$ & 0 & 0.15 & $1.32(0.17,2.47)$ & 86 & 0.02 \\
\hline Mixed & $0.19(-0.43,0.80)$ & 0 & 0.55 & $-0.84(-1.38,-0.29)$ & 7 & 0.003 \\
\hline \multicolumn{7}{|l|}{ BMI } \\
\hline $\mathrm{BMI} \leq 25$ & $0.82(-11.12,12.76)$ & 89 & 0.89 & $-0.73(-3.52,2.06)$ & 58 & 0.61 \\
\hline $\mathrm{BMI}>25$ & $0.22(-0.35,0.79)$ & 0 & 0.44 & $0.52(-1.82,2.86)$ & 98 & 0.66 \\
\hline \multicolumn{7}{|c|}{ Intervention period } \\
\hline$<12$ months & $3.23(-2.96,9.42)$ & 87 & 0.31 & $-0.04(-2.14,2.06)$ & 68 & 0.97 \\
\hline 12-24 months & $2.44(-3.94,8.82)$ & 84 & 0.45 & $-1.17(-3.70,1.36)$ & 83 & 0.37 \\
\hline$>24$ months & $0.18(-1.36,1.72)$ & 0 & 0.82 & $4.19(-2.75,11.12)$ & 97 & 0.24 \\
\hline \multicolumn{7}{|l|}{ Course of DM } \\
\hline$\leq 10$ years & $1.83(-0.44,4.10)$ & 0 & 0.11 & $3.93(-0.33,8.19)$ & 88 & 0.07 \\
\hline$>10$ years & $1.87(-1.19,4.93)$ & 85 & 0.23 & $-2.14(-4.29,0.01)$ & 87 & 0.05 \\
\hline
\end{tabular}

BMI body mass index, GFR glomerular filtration rate, T1DM type 1 diabetes mellitus, T2DM type 2 diabetes mellitus 


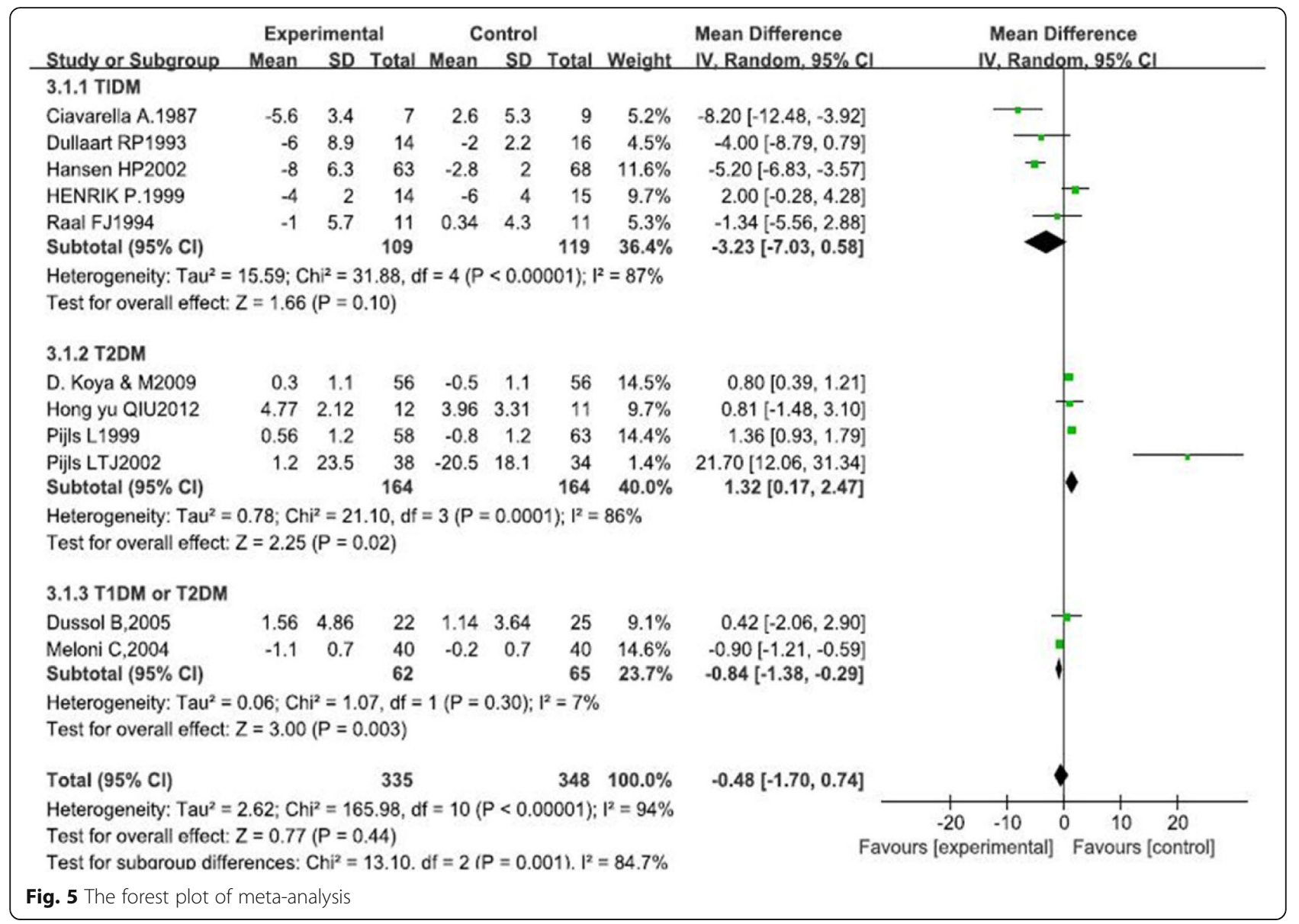

\section{Conclusions}

In conclusion, the present research indicates that LPD has not conspicuously shown renoprotective effects in diabetic nephropathy. In future, we should merge our current knowledge of molecular genetics to reanalyze how an LPD works and determine the specific underlying molecular mechanisms. Meanwhile, large multicenter RCTs should be carried out to better understand the actual effect of an LPD on kidney outcomes in diabetic nephropathy.

\section{Abbreviations}

ACE-Is: Angiotensin-Converting Enzyme Inhibitors; ARBs: angiotensin receptor blockers; CCR: creatinine filtration rate; Cl: confidence intervals; DN: diabetic nephropathy; ESRD: end-stage kidney disease; GFR: glomerular filtration rate; LPD: low-protein diet; SD: standard deviation; SMD: standardized mean difference

\section{Funding}

This work was funded by National Natural Science Foundation of China Grants (No. 81670757, No. 81570742), Natural Science Foundation of

Shandong Province (No.ZR2016HQ26); grant for the development of science and technology of JiNan City (No. 201602172).

\section{Availability of data and materials}

Data sharing not applicable to this article as no datasets were generated or analysed during the current study.

\section{Authors' contributions}

$\mathrm{HZ}$ and ZJ collect relevant information and analyzed the data. PG, DZ, ZZ, $\mathrm{Q}-\mathrm{Z}, \mathrm{HM}, \mathrm{ZG}, \mathrm{JZ}$ have been involved in revising it critically for important intellectual content; $\mathrm{LL}$ and Jd wrote the paper. All authors read and approved the final manuscript.

Ethics approval and consent to participate

Not applicable.

\section{Competing interests}

The authors declare that they have no competing interests.

\section{Publisher's Note}

Springer Nature remains neutral with regard to jurisdictional claims in published maps and institutional affiliations.

\section{Author details}

'Division of Endocrinology, Qilu Hospital of Shandong University, Jinan, Shandong, China. ${ }^{2}$ Division of Endocrinology, The Ninth Hospital of Xi An, Shan xi, China. ${ }^{3}$ Division of Endocrinology, The General Hospital of Jinan Military Command, 25 Shifan Road, Jinan 250031, Shandong, China. ${ }^{4}$ Division of Endocrinology, Shandong Provincial Qianfoshan Hospital, Jinan, Shandong, China. Internal medicine department, Guanxian hospital of traditional Chinese medicine, Liaocheng, Shandong, China.

Received: 15 August 2017 Accepted: 28 May 2018

Published online: 19 June 2018

\section{References}

1. Packham DK, Alves TP, Dwyer JP, et al. Relative incidence of ESRD versus cardiovascular mortality in proteinuric type 2 diabetes and nephropathy: results from the DIAMETRIC (Diabetes Mellitus Treatment for Renal Insufficiency Consortium) database. Am J Kidney Dis. 2012;59:75-83. 
2. Valmadrid CT, Klein R, Moss SE, et al. The risk of cardiovascular disease mortality associated with microalbuminuria and gross proteinuria in persons with older-onset diabetes mellitus. Arch Inter Med. 2000;160:1093-100.

3. Association AD. Nutritional recommendations and interventions for diabetes. A position statement of the American Diabetes Association. Diabetes Care. 2008;30(Suppl 1):S61-78.

4. Molitch ME, DeFronzo RA, Franz MJ, et al. Diabetic nephropathy. Diabetes Care. 2003;26(Suppl 1):S94-8.

5. American Diabetes Association. Standards of medical care in diabetes-2013. Diabetes Care. 2012;36:S11-66.

6. Kitada M, Kanasaki K, Koya D. Clinical therapeutic strategies for early stage of diabetic kidney disease. World J Diabetes. 2014;5:342-56.

7. Koya D, Haneda M. Inomata S et al (2009) long-term effect of modification of dietary protein intake on the progression of diabetic nephropathy: a randomised controlled trial. Diabetologia. 2009;52:2037-45.

8. Johnson DW. Dietary protein restriction as a treatment for slowing chronic kidney disease progression: the case against. Nephrology. 2006;11:58-62.

9. Robertson L, Waugh N, Robertson A. Protein restriction for diabetic renal disease. Cochrane Database Syst Rev. 2007:4:CD002181.

10. Klahr S, Levey AS, Beck GJ, et al. The effects of dietary protein restriction and blood-pressure control on the progression of chronic renal disease. Modification of diet in renal disease study group. N Engl J Med. 1994:330:877-84.

11. Levey AS, Greene T, Beck GJ, et al. Dietary protein restriction and the progression of chronic renal disease: what have all of the results of the MDRD study shown? Modification of diet in renal disease study group. J Am Soc Nephrol. 1999;10:2426-39.

12. Levey AS, Greene T, Sarnak MJ, et al. Effect of dietary protein restriction on the progression of kidney disease: long-term follow-up of the modification of diet in renal disease (MDRD) study. Am J Kidney Dis. 2006:48:879-88.

13. Hansen HP, Tauber-Lassen E, Jensen BR, Parving HH. Effect of dietary protein restriction on prognosis in patients with diabetic nephropathy. Kidney Int. 2002;62:220-8.

14. Pedrini MT, Levey AS, Lau J, Chalmers TC, Wang PH. The effect of dietary protein restriction on the progression of diabetic and nondiabetic renal diseases: a meta-analysis. Ann Intern Med. 1996;124:627-32.

15. Locatelli F, Alberti D, Graziani G, Buccianti G, Redaelli B, Giangrande A. Prospective, randomised, multicentre trial of effect of protein restriction on progression of chronic renal insufficiency. Northern Italian Cooperative Study Group. Lancet 1991;337:1299-1304.

16. Merforth S, Osmers A, Dahlmann B. Alterations of proteasome activities in skeletal muscle tissue of diabetic rats. Mol Biol Rep. 1999;26:83-7.

17. JPT H, Green S. Cochrane handbook for systematic reviews of interventions 4.2.7. In: The Cochrane Library, Issue 3. Chichester, United Kingdom: Wiley; 2005.

18. .Cochrane Handbook for Systematic Reviews of Interventions. http:// handbook.cochrane.org/ (accessed 11 Dec 2012).

19. Solon-Biet SM, MCMahon AC, Ballard JWO, Ruohonen K, Wu LE, Cogger VC, et al. The ratio of macronutrients, not caloric intake, dictates Cardiometabolic health, aging, and longevity in ad libitum-fed mice. Cell Metab. 2014;19:418-30.

20. Sakaguchi M, Isono M, Isshiki K, Sugimoto T, Koya D, Kashiwagi A. Inhibition of mTOR signaling with rapamycin attenuates renal hypertrophy in the early diabetic mice. Biochem Biophys Res Commun. 2006;340:296-301.

21. Kitada M, Ogura Y, Suzuki T, et al. A very-low-protein diet ameliorates advanced diabetic nephropathy through autophagy induction by suppression of the mTORC1 pathway in Wistar fatty rats, an animal model of type 2 diabetes and obesity. Diabetologia. 2016; https://doi.org/10.1007/ s00125-016-3925-4.

22. Premen AJ. Protein-mediated elevations in renal hemodynamics: existence of a hepato-renal axis? Med Hypotheses. 1986;19:295-309.

23. Ueda J, Nakanishi H, Miyazaki M, Abe Y. Effects of glucagon on the renal hemodynamics in the dog. Jpn Circ J. 1977;41:991-8.

24. Fontana L, Weiss EP, Villareal DT, Klein S, Holloszy JO. Longterm effects of calorie or protein restriction on serum IGF-1 and IGFBP-3 concentration in humans. Aging Cell. 2008;7:681-7.

25. Tonshoff B, Kaskel FJ, Moore LC. Effects of insulin-like growth factor I on the renal juxtamedullary microvasculature. Am J Physiol. 1998;274:F120-8.

26. Tsukahara H, Gordienko DV, Tonshoff B, Gelato MC, Goligorsky MS. Direct demonstration of insulin-like growth factor--induced nitric oxide production by endothelial cells. Kidney Int. 1994;45:598-604.
27. Martinez-Maldonado M, Benabe JE, Wilcox JN, Wang S, Luo C. Renal renin, angiotensinogen, and ANG I-converting-enzyme gene expression: influence of dietary protein. Am J Physiol. 1993;264:F981-8.

28. Benabe JE, Fernandez-Repollet E, Tapia E, Luo C, Martinez- Maldonado M. Angiotensin II and catecholamines interaction in short-term low protein feeding. Kidney Int. 1993;44:285-93.

29. Benabe JE, Wang S, Wilcox JN, Martinez-Maldonado M. Modulation of ANG II receptor and its mRNA in normal rat by low-protein feeding. Am J Phys. 1993;265:F660-9.

30. Dunkler D, Dehghan M, Teo KK, Heinze G, Gao P, Kohl M, et al. Diet and kidney disease in high-risk individuals with type 2 diabetes mellitus. JAMA Intern Med. 2013;173:1682-92.

31. Chronic Kidney Disease: National Clinical Guideline for Early Identification and Management in Adults in Primary and Secondary Care National Collaborating Centre for Chronic Conditions (UK).London: Royal College of Physicians (UK). 2008; PMID:21413194.

32. Andrassy KM. Comments on 'KDIGO 2012 clinical practice guideline for the evaluation and management of chronic kidney disease'. Kidney Int. 2013;84:622-3.

33. Arimura E, Horiuchi M, Kawaguchi H, Miyoshi N, Aoyama K, Takeuch T. Low-protein diet improves blood and urinary glucose levels and renal manifestations of diabetes in C57BLKS-db/db mice. Eur J Nutr. 2013;52:813-24.

34. Freeman PR. The performance of the two-stage analysis of two treatment two-period cross-over trials. Stat Med. 1989:8:1421-32.

35. Ciavarella A, Di Mizio G, Stefoni S, Borgnino LC, Vannini P. Reduced albuminuria after dietary protein restriction in insulin-dependent diabetic patients with clinical nephropathy. Diabetes Care. 1987;10:407-13.

36. Dullaart RP, Beusekamp BJ, Meijer S, van Doormaal JJ, Sluiter WJ. Long-term effects of protein-restricted diet on albuminuria and renal function in IDDM patients without clinical nephropathy and hypertension. Diabetes Care. 1993;16:483-91.

37. Raal FJ, Kalk WJ, Lawson M, et al. Effect of moderate dietary protein restriction on the progression of overt diabetic nephropathy: a 6-mo prospective study. Am J Clin Nutr. 1994;60:579-85.

38. Pijls LT, de Vries H, Donker A, van Eijk JT. The effect of protein restriction on albuminuria in patients with type 2 diabetes mellitus: a randomized trial. Nephrol Dial Transplant. 1999;14:1445-53.

39. Hansen HP, Christensen PK, Tauber-Lassen E, et al. Low-protein diet and kidney function in insulin-dependent diabetic patients with diabetic nephropathy. Kidney Int. 1999;55:621-8.

40. Pijls LT, de Vries H, van Eijk J, Donker AJ. Protein restriction, glomerular filtration rate and albuminuria in patients with type 2 diabetes mellitus: a randomized trial. Eur J Clinic Nutr. 2002;56:1200-7.

41. Meloni C, Tatangelo P, Cipriani S, et al. Adequate protein dietary restriction in diabetic and nondiabetic patients with chronic renal failure. J Ren Nutr. 2004;14:208-13.

42. Dussol B, lovanna C, Raccah D, et al. A randomized trial of low-protein diet in type 1 and type 2 diabetes mellitus patients with incipient and overt nephropathy. J Ren Nutr. 2005;15:398-406.

43. Koya D, Haneda M, Inomata S, et al. Long-term effect of modification of dietary protein intake on the progression of diabetic nephropathy: a randomized controlled trial. Diabetologia. 2009;52:2037-45.

44. Qiu HY, Liu F, Zhao LJ, Huang SM, Zuo C, Zhong H, Chen F. Comparison of the effects of alpha-keto/ amino acid supplemented low protein diet and diabetes diet in patients with diabetic nephropathy. Sichuan Da Xue Xue Bao Yi Xue Ban. 2012:43(3):425-8. 